\title{
IMPLEMENTASI MODUL PENJASORKES BERMUATAN MODEL PEMBELAJARAN BANDURA UNTUK MENINGKATKAN HASIL BELAJAR PENJASORKES DAN KECERDASAN KINESTETIK SISWA SEKOLAH DASAR
}

\author{
I Ketut Yoda ${ }^{1}$ \\ ${ }^{1}$ Program Studi Ilmu Keolahragaan \\ Universitas Pendidikan Ganesha Bali, Indonesia \\ email: yodaketut@gmail.com
}

\begin{abstract}
Abstrak
Penelitian bertujuan untuk mengimplementasikan modul penjasorkes bermuatan model pembelajaran Bandura dalam meningkatkan hasil belajar penjasorkes dan kecerdasan kinestetik siswa sekolah dasar. Populasi dalam penelitian ini adalah siswa SD Laboratorium kelas IV. Penelitian ini menggunakan metode eksperimen semu dengan teknik pengambilan sampel random sampling. Jumlah sampel yang digunakan satu kelas yang berjumlah 29 orang. Analisis data dilakukan secara deskriptif dengan cara menyusun data secara sistematis, mengorganisasi data ke dalam kategori, melakukan sintesa, menyusun dalam pola tertentu, dan membuat kesimpulan. Hasil analisis data di peroleh bahwa modul penjasorkes bermuatan model pembelajaran Bandura yang diterapkan di kelas IV Sekolah Dasar Laboratorium Undiksha Singaraja menunjukkan hasil belajar yang baik dengan peningkatan kecerdasan kinestetik juga baik. Respon siswa menunjukkan bahwa $100 \%$ siswa menyatakan modul penjasorkes bermuatan model pembelajaran Bandura dapat dengan mudah dipahami dalam melatih keterampilan gerak dan kecerdasan kenestetis siswa.
\end{abstract}

Kata-kata kunci: modul, pembelajaran, bandura, penjasorkes.

\begin{abstract}
Research aims to implement the Module Physical Education and Health Containing of Bandura Learning Model for Improving Learning Outcomes and Kinesthetic intelligence of Elementary School Students. The population in this study was a grade IV Elementary student of Laboratory School. The study used quasy-experimental methods with random sampling techniques. The number of samples used one class numbering 29 people. Data analysis is done descriptively by systematically composing data, organizing data into categories, performing syntheses, composing in certain patterns, and making conclusions. The results of the data analysis were obtained that the module of physical education and health cotaining of Bandura learning model applied in grade IV of Elementary School Laboratory Undiksha Singaraja showed good learning results with improved kinesthetic intelligence also well. The student response showed that $100 \%$ of students stated the module physical education and health containing of bandura learning model, could be easily understood in training motor skills and kinesthetic intelligence of students.
\end{abstract}

Keywords: module, learning, bandura, physical education and health 


\section{PENDAHULUAN}

Penjasorkes pada hakikatnya
adalah proses pendidikan yang
memanfaatkan aktivitas fisik untuk menghasilkan perubahan holistic dalam kualitas individu, baik dalam hal fisik, mental, serta emosional. Penjasorkes memperlakukan anak sebagai sebuah kesatuan utuh, mahluk total, dari pada hanya menganggapnya sebagai seseorang yang terpisah kualitas fisik dan mentalnya (Mahendra, 2007).

Rendahnya kualitas pembelajaran penjasorkes yang berimplikasi terhadap rendahnya hasil belajar dan kecerdasan kinestetik siswa SD disebabkan karena rendahnya kualitas guru penjasorkes, dan terbatasnya sumber belajar (Mutohir, 2002). Kecerdasan kinestetik merupakan salah satu kecerdasan yang harus dikembangkan sejak dini. Hal ini disebabkan karena perkembangan manusia dari prenatal hingga post natal, semua berawal dari gerak. Tanpa gerak maka manusia tidak bisa hidup. Gerak juga dapat dipakai sebagai indikator untuk mengetahui apakah perkembangan kecerdasan intelektual, sosial, dan emosional seseorang baik atau jelek. Pengembangan kecerdasan kinestetik yang diimplementasikan melalui pembelajaran gerak akan memberikan kontribusi pada aspek yang lain seperti; belajar menghargai perbedaan, menghargai diri sendiri dan orang lain, kejujuran dan keterbukaan, pengontrolan diri dan emosional, kesehatan badan dan kebugaran tubuh, bekerjasama dalam kelompok dan belajar bersosialisasi, serta belajar berkompetisi secara sehat (Muhyi Faruq M, 2007).

Hasil wawancara dengan guru-guru penjasorkes di Kabupaten Buleleng dimana para guru penjasorkes sangat susah mencari buku sumber dan panduan untuk pelaksanaan pembelajaran penjasorkes di SD. Kurangnya sumber-sumber belajar tersebut juga membawa dampak terhadap kurangnya pemahaman dan kemampuan guru penjasorkes di Kabupaten Buleleng dalam memilih dan menerapkan metode pembelajaran penjasorkes. Hasil wawancara dengan beberapa guru penjasorkes SD di Kabupaten Buleleng hampir semua guru tidak mengenal apa yang dimaksud dengan model pembelajaran Bandura.

Kondisi sulitnya mencari sumber belajar penjasorkes terutama pada sekolah dasar yang berada di pedesaan baik berupa buku maupun dalam bentuk modul juga memberikan kontribusi pada kurang berkualitasnya pelaksanaan pembelajaran penjasorkes. Dalam upaya meningkatkan kualitas dan hasil belajar penjasorkes di SD, sumber belajar yang paling mudah dipelajari baik untuk siswa maupun guru penjasorkes adalah berupa modul. Russel (1974) mendefinisikan modul sebagai berikut: "A module is an instructional package dealing with a single conceptual unit of subject matter", sedangkan Warwich (1996) mendefinisikan modul sebagai suatu unit materi kurikulum yang lengkap, dan dapat ditambah dengan pencapaian tugas yang lebih besar atau tujuan-tujuan jangka panjang. Modul sebagai bahan pembelajaran memiliki struktur yang khas, terdiri dari pendahuluan yang berisi uraian singkat tentang cakupan materi modul, tujuan pembelajaran, perilaku awal (jika ada), petunjuk belajar keterkaitan/manfaat modul bagi siswa, dan urutan bahasan (kegiatan belajar). Pada kegiatan belajar berisi sajian materi, contoh, latihan serta rangkuman yang bersifat interaktif untuk menumbuhkan pembelajaran (Winataputra, dkk, 1997). Modul diharapkan disusun sedemikian rupa agar memungkinkan: 1) meningkatkan secara maksimal kegiatan pembelajaran, 2) terselenggaranya proses maju berkelanjutan secara efektif, 3) pembelajaran berpusat pada siswa (Depdikbud, 1985). Suatu modul yang disusun dengan baik dapat memberikan banyak keuntungan, yaitu: 1) dapat 
meningkatkan secara maksimal pembelajaran, 2) siswa lebih aktif dalam proses belajarnya karena menghadapi sejumlah masalah atau tugas yang harus dikerjakan, 3) dapat memberikan balikan dengan segera sehingga siswa dapat mengetahui hasil belajarnya, 4) kegiatan siswa terarah, karena modul mengandung sasaran belajar yang jelas, dan 5) keterlibatan guru dalam pembelajaran sangat minimal (Russel,1974; Suryobroto, 1983 dan Nasution 2000).

Pembelajaran penjasorkes hendaknya dirancang dalam suatu proses pembelajaran yang produktif, aktif, inovatif, kreatif, efektif dan menyenangkan, karena pembelajaran penjasorkes yang benar akan mampu meningkatkan berbagai kecerdasan secara holistik, yakni kecerdasan intelektual, kecerdasan spiritual, kecerdasan sosial dan emosional, dan kecerdasan kinestetik.

Sebagai alternatif pemecahan permasalahan tersebut di atas, maka solusi yang ditawarkan dalam penelitian ini adalah pengembangan modul bermuatan model pembelajaran Bandura. Hal ini disebabkan karena modul sebagai suatu unit materi kurikulum yang lengkap, dapat juga ditambah dengan pencapaian tugas yang lebih besar atau tujuan-tujuan jangka panjang dan sangat mudah dipahami oleh guru-guru penjasorkes terutama bagi guru penjasorkes yang tidak memiliki kualifikasi akademik dalam bidangnya. Modul juga akan sangat membantu guruguru penjasorkes yang sulit mencari sumber belajar terutama pada sekolah SD di pedesaan.

Sementara itu dengan model pembelajaran Bandura akan sangat memudahkan siswa untuk menyerap materi pelajaran, karena dalam kegiatan pembelajaran akan dirancang melalui pengamatan melibatkan proses pemodelan (modeling) dan peniruan (imitation). Hal ini dilakukan mengingat sebagian besar yang dipelajari manusia kebanyakan terjadi melalui peniruan (imitation) dan penyajian contoh perilaku (modeling), sehingga sangat sesuai dengan karakteristik perkebangan emosi, adapatasi sosial, mental, dan gerak anak SD.

Kebutuhan akan metode yang efisien dalam pembelajaran penjasorkes dilandasi oleh beberapa alasan: pertama, Efisiensi akan menghemat waktu, energi atau biaya; kedua, metode efisien akan memungkinkan para siswa untuk menguasai tingkat keterampilan yang lebih tinggi (Rusli Lutan, 1988). Salah satu model pembelajaran yang dapat digunakan adalah model pembelajaran pengamatan (observasional learning) yang dikembangkan oleh Albert Bandura. Model pembelajaran ini termasuk rumpun model pembelajaran sistem perilaku yang orientasi pokoknya adalah belajar sosial dan dikembangkan oleh Albert Bandura, seorang behaviorist moderat dari Universitas Stanford Amerika Serikat. Penggunaan model pembelajaran pada hakikatnya untuk membantu siswa memperoleh informasi, gagasan, keterampilan, nilai, cara berpikir, dan cara bagaimana belajar (Joyce \& Weil, 1996). Pembelajaran melalui pengamatan adalah belajar melalui pengamatan dan imitasi terhadap perilaku yang diamati (Slavin, 1997). Eggen \& Kauchak (1996), menguraikan bahwa pembelajaran melalui pengamatan meliputi perubahan perilaku, berpikir, emosi hasil pengamatan perilaku model. Di samping itu, hasil yang dapat diperoleh dari pembelajaran melalui pengamatan adalah (1) mengajarkan perilaku dan sikap baru, (2) mendorong perilaku yang telah ada, (3) mengubah perilaku yang menghambat, mengarahkan perhatian, dan (5) mengembangkan reaksi emosional (Woolfolk, 1995).

Kegiatan pembelajaran melalui pengamatan melibatkan proses pemodelan (modeling) dan peniruan (imitation). Hal ini dilakukan mengingat sebagian besar yang dipelajari manusia kebanyakan terjadi melalui peniruan (imitation) dan 
penyajian contoh perilaku (modeling). Menurut Bandura (1977; 1996), ada empat proses penting yang dapat diperhatikan dalam pembelajaran melalui pengamatan.

\section{Atensi. Pebelajar (observer)} memusatkan perhatian atau atensi pada objek materi atau perilaku model atau pelatih. Atensi dipengaruhi oleh kompleksitas dan relevansinya bagi pebelajar (Gredler, 1991). Menurut hasil penelitian Bandura, pebelajar akan dapat memperhatikan perilaku dengan baik apabila tingkah laku tersebut jelas dan tidak terlampau kompleks. Pelatih dapat membagi keterampilan kompleks, misalnya membelajarkan servis tenis menjadi beberapa bagian, misalnya cara memegang raket, melempar bola, dan mengayun (Arends, 1997).

2. Retensi. Pebelajar mengingat apa yang diamati. Menurut teori belajar kognitif, mengingat berarti menyimpan apa yang diamati dalam memori jangka panjang. Pebelajar menyimpan hasil observasi dengan kode simbolik (Elliott et al., 1996). Retensi dapat diperbaiki dengan pengulangan secara mental (membayangkan meniru perilaku yang di amati) atau dengan latihan (Woolfolk, 1995). Untuk memastikan terjadinya retensi jangka panjang, pelatih dapat menyediakan peroide pelatihan, yang memungkinkan siswa mengulang keterampilan baru secara bergiliran, baik secara fisik maupun secara mental (Arends, 1997).

3. Reproduksi. Dalam proses reproduksi, pebelajar berusaha mereproduksi objek materi atau model yang telah diamati dan disimpan. Hasil reproduksi dapat digunakan untuk mengases hasil belajar. Pada tahap ini dapat dilakukan "pemodelan korektif". Keterampilan yang dilakukan apabila kurang benar perlu dikoreksi dengan melakukan pemodelan kinerja yang benar, kemudian meminta pebelajar mengulangi sampai benar-benar menguasai (Arends, 1997)

4. Motivasi. Proses terakhir dalam pembelajaran melalui pengamatan adalah proses motivasi yang dapat berfungsi sebagai perolehan reinforcement (penguatan). Pemberian penguatan dapat berupa hadiah, pujian, bonus nilai atau bentuk lain.

\section{METODE}

Populasi dalam penelitian ini adalah siswa SD Laboratorium kelas IV. Penelitian ini menggunakan metode eksperimen semu dengan teknik pengambilan sampel random sampling. Jumlah sampel yang digunakan satu kelas yang berjumlah 29 orang. Data yang telah dikumpulkan akan disajikan dalam bentuk tabel dan narasi. Analisis data dilakukan secara deskriptif dengan cara menyusun data secara sistematis, mengorganisasi data ke dalam kategori, melakukan sintesa, menyusun dalam pola tertentu, dan membuat kesimpulan. Ringkasan analisis hasil implementasi dapat diuraikan sebagai berikut: (1) analisis hasil belajar (kognitif, afektif, dan psikomotor), mengenai ketentuntasan belajar dianalisis secara deskriptif sesuai dengan kriteria ketuntasan minimal (KKM) yang berlaku pada masing-masing sekolah, (2) analisis data aktivitas siswa dalam pembelajaran: data tentang respon siswa. Respon siswa terhadap pembelajaran menggunakan asesmen otentik dan model kerja ilmiah dianalisis secara deskriptif. Setiap jawaban (respon) siswa terhadap pertanyaan pada kuesioner dihitung persentasenya. Persentase setiap respon ditentukan berdasarkan jumlah respon siswa setiap aspek dibagi dengan jumlah seluruh siswa dikali $100 \%$, (4) analisis kecerdasan kinestetik siswa digunakan kriteria yang terdapat dalam tabel konversi sesuai dengan jenis kecerdasan kinestetik tersebut. 
HASIL DAN PEMBAHASAN

\section{Hasil}

Data hasil belajar siswa menggunakan model pembelajaran bandura, kecerdasan kinestetik dan respon terhadap pembelajaran Penjasorkes dapat diuraikan pada tabel 1, 2, dan 3 berikut.

Tabel 1 Hasil Belajar Siswa Kelas IV SD Laboratorium Singaraja -Bali (skala 100, n=29)

\begin{tabular}{ccc}
\hline No. & Deskripsi Data & Hasil Belajar \\
\hline 1 & Rerata & 85,69 \\
2 & Simpangan Baku & 8,52 \\
3 & Ketuntasan/Kriteria*) & 100 \\
\hline
\end{tabular}

*) Ketuntasan persentase siswa yang memenuhi criteria ketuntasan minimal 75

Tabel 2 Kecerdasan Kinestetik Siswa Kelas IV SD Laboratorium Singaraja -Bali ( $\mathrm{n}=29)$

\begin{tabular}{lll}
\hline No. & \multicolumn{1}{c}{ Kecerdasan Kinestetis } & \multicolumn{1}{c}{ Hasil Penelitian } \\
\hline 1 & Kecepatan & Baik sekali 68,97\% (20 orang) \\
& & Baik 24,14\% (7 orang) \\
& & Cukup 6,89\% (2 orang) \\
& & Kurang 0\% \\
& & Kurang sekali 0\% \\
& & Baik sekali 51,72\% (15 orang) \\
& Kelincahan & Baik 34,48\% (10 orang) \\
& & Cukup 13,79\% (4 orang) \\
& & Kurang 0\% \\
& & Kurang sekali 0\% \\
& & Baik sekali 34,48\% (10 orang) \\
& Daya ledak otot tungkai & Baik 48,28\% (14 orang) \\
& & Cukup 17,24\% (5 orang) \\
& & Kurang 0\% \\
& & Kurang sekali 0\% \\
& & Baik sekali 17,24\% (5 orang) \\
& Kelentukan togok & Baik 44,83\% (13 orang) \\
& & Cukup 37,93\% (11 orang) \\
& Kurang 3,45\% (1 orang) \\
\hline
\end{tabular}


Tabel 3 Respon Siswa terhadap Pembelajaran Penjasorkes Menggunakan Modul Penjasorkes Bermuatan Model Pembelajaran Bandura

Respon Siswa

No.

Pertanyaan

Frekuensi

Persentase

$(\%)$

1 Bagaimana pendapat anda mengenai pembelajaran menggunakan modul penjasorkes bermuatan model Pembelajaran Bandura?

a. Pelaksanaan pembelajaran

* Menyenangkan

* Tidak menyenangkan

29

0

100

b. Kemenarikan pembelajaran

* Menarik

29

0

100

* Tidak menarik

c. Pembelajaran yang dibelajarkan

* Mudah dipahami

27

93,1

* Sulit dipelajari

d. Tugas-tugas yang diberikan dalam pembelajaran

* Menantang

Tidak menantang

e. Asesemen dan evaluasi

* Terbuka/objektif

* Tidak terbuka

2 Bagaimanakah pendapat anda tentang modul penjasorkes bermuatan model pembelajaran Bandura?

a. Membantu melatih kecerdasan kinestetik

* Ya

* Tidak

b. Mendorong belajar secara aktif

* Ya

* Tidak

c. Memotivasi belajar

* Ya

* Tidak

d. Mendorong saling bekerja sama

* Ya

* Tidak

96,55

3,45

Modul penjasorkes bermuatan model pembelajaran Bandura yang diterapkan di kelas IV Sekolah Dasar Laboratorium Undiksha Singaraja menunjukkan hasil belajar yang baik dan peningkatan kecerdasan kinestetikpun juga baik. Rerata hasil belajar penjasorkes siswa adalah 85,69, sementara unsur kecerdasan kinestetis adalah: Kecepatan; Baik sekali 68,97\% (20 orang); Baik 24,14\% (7 orang); Cukup 6,89\% (2 orang), (2) Kelincahan; Baik sekali $51,72 \%$ (15 orang); Baik 34,48\% (10 orang); Cukup 13,79\% (4 orang), (3) Daya 
ledak otot tungkai; Baik sekali 34,48\% (10 orang); Baik 48,28\% (14 orang); Cukup $17,24 \%$ (5 orang), (4) Kelentukan togok; Baik sekali $17,24 \%$ (5 orang); Baik $44,83 \%$ (13 orang); Cukup 37,93\% (11 orang); Kurang 3,45\% (1 orang).

Keberhasilan disebabkan karena modul penjasorkes bermuatan model pembelajaran bandura adalah sebuah modul yang yang memiliki sistimatika sedemikian rupa yang memungkinkan siswa belajar secara bertahap dari menyimak dan berupaya memahami apa yang disampaikan oleh guru (atensi), kemudian diproses dalam struktur kognitif untuk dapat menyimpan dalam memori (retensi), dan selanjutnya informasi yang telah tersimpan dalam memori tersebut kemudian diwujudkan dalam suatu gerak keterampilan. Hal ini juga didukung oleh data respon siswa yang menunjukkan bahwa $100 \%$ siswa menyatakan bahwa modul penjasorkes bermuatan model pembelajaran Bandura dapat dengan mudah dipahami dalam melatih keterampilan gerak dan kecerdasan kenestetis siswa. Penjasorkes sebagai bagian yang tidak terpisahkan dari pendidikan secara keseluruhan memiliki peran sebagai pondasi bagi tumbuh kembang anak. Dengan demikian, penjasorkes dapat mengembangkan seluruh potensi yang dimiliki anak yakni aspek organis, perseptual, kognitif, sosial dan emosional.

Menurut Suherman (2007), kekhasan penjasorkes dapat digunakan sebagai landasan yang kokoh bagi anak, diperlukan agar anak memiliki kondisi jasmani, intelektual dan mental spiritual yang memadai untuk berkembang lebih lanjut sesuai dengan potensi masingmasing.

Dengan metode dan modul yang efisien dalam pembelajaran penjasorkes akan memungkinkan: pertama, Efisiensi akan menghemat waktu, energi atau biaya; kedua, metode efisien akan memungkinkan para siswa untuk menguasai tingkat keterampilan yang lebih tinggi (Rusli Lutan, 1988). Salah satu model pembelajaran yang dapat digunakan adalah model pembelajaran pengamatan (observasional learning) yang dikembangkan oleh Albert Bandura. Model pembelajaran ini termasuk rumpun model pembelajaran sistem perilaku yang orientasi pokoknya adalah belajar sosial dan dikembangkan oleh Albert Bandura, seorang behaviorist moderat dari Universitas Stanford Amerika Serikat. Penggunaan model pembelajaran pada hakikatnya untuk membantu siswa memperoleh informasi, gagasan, keterampilan, nilai, cara berpikir, dan cara bagaimana belajar (Joyce \& Weil, 1996). Pembelajaran melalui pengamatan adalah belajar melalui pengamatan dan imitasi terhadap perilaku yang diamati (Slavin, 1997). Eggen \& Kauchak (1996), menguraikan bahwa pembelajaran melalui pengamatan meliputi perubahan perilaku, berpikir, emosi hasil pengamatan perilaku model. Di samping itu, hasil yang dapat diperoleh dari pembelajaran melalui pengamatan adalah (1) mengajarkan perilaku dan sikap baru, (2) mendorong perilaku yang telah ada, (3) mengubah perilaku yang menghambat, mengarahkan perhatian, dan mengembangkan reaksi emosional (Woolfolk, 1995).

\section{SIMPULAN DAN SARAN}

Hasil uji coba penerapan modul penjasorkes bermuatan model pembelajaran Bandura pada siswa kelas IV SD menunjukkan bahwa:

1. Penerapan modul penjasorkes bermuatan model pembelajaran Bandura dapat meningkatkan hasil belajar penjasorkes dan kecerdasan kinestetis siswa.

2. Respon siswa terhadap pembelajaran penjasorkes dengan menerapkan modul bermuatan model pembelajaran Bandura, sangat positif. Pembelajaran 
penjasorkes menjadi menyenangkan, menarik, mudah dipahami, tugas-tugas menantang, assessemen dan evaluasi obyektif dan terbuka, dan mendorong siswa belajar secara aktif yaitu aktif berpikir dan aktif melakukan latihan keterampilan gerak.

Untuk meningkatkan hasil belajar penjasorkes dan keterampilan kinestetis siswa kelas IV SD, dapat menggunakan modul penjasorkes bermuatan model pembelajaran Bandura yang dilengkapi dengan buku pedoman petunjuk guru. Agar penggunaan modul dapat berhasil dengan baik, maka perlu memperhatikan hal-hal sebagai berikut.

(1) Guru sebaiknya memahami konsep tentang teori belajar menurut Bandura dan menguasai materi ajar secara luas dan mendalam.

(2) Guru diharapkan dapat memberikan informasi yang sejelas-jelasnya tentang substansi materi yang diberikan kepada siswa ketika tahap atensi.

(3) Guru diharapkan memberikan kesempatan kepada siswa berlatih menggunakan alat yang diperlukan dalam tahap reproduksi.

(4) Pembelajaran disesuaikan dengan buku pedoman umum penggunaan modul dan petunjuk guru.

\section{DAFTAR PUSTAKA}

Arends, R.E. 1997. Classroom Instruction and Management. New York: McGraw-Hill.

Bandura, A. 1996. Social Learning Theory of Human Development. In De Corte, E. and Weinert, F.E. (Eds.) 1996. International Encyclopedia of Developmental and Instructional Psychology. Oxpord: Pergamon. pp: 101106.

Callahan, JF; Clark, L.H. \& R.D. Kellough. 1992. Teaching in The Middle and Secondary
Schools, $4^{\text {th }}$ ed. New York: macmillan.

Cavill, N., Biddle, S. J. H,. \& Sallis, J. F. 2001. Health Enhancing Physical Activity for Young People: Statement of the United Kingdom expert consensus cnference. Pediatric Exercise Science.

Dreher, M.J. and H. Singer. 1989. Frendly Texts and Texs Frendly. Theory into Practice, XXVIII (2): 98-104

Eggen, P.D and Kauchak, D.P. 1996. Strategy for Teaching Content and Thinking Skills. Boston:Allyn \& Bacon.

Elliott, S.; Kratochwill, T.R.; Littlefield, J. and Travers, J.F. 1996. Educational Psychology: Effective Teaching, Effective Learning. Madison: Brown \&

Gredler, M. E. B. 1991. Belajar dan Pembelajaran. Terjemahan. Jakarta: Rajawali Pers.

Hackbarth,S. 1996. The Educational Technology Handbooks: A Comprehesive Guide: Process and Products fo Learning. New Jersey: Educational Technology Publication, Inc.

Joyce, B. and Weil, M. 1996. Models of Teaching. Boston: Allyn and Bacon.

Muhyi Faruq, M. 2007. 100 Permainan Kecerdasan Kinestetik. Jakarta: PT Gramedia Widia Sarana Indonesia.

Mutohir, Toho Cholik. 2002. Gagasangagasan Tentang Pendidikan Jasmani Dan Olahraga. Surabaya: Unesa University Press.

Mutohir, Toho Cholik dan Ali Maksum. 2007. Sport Development Index: Konsep-Metodologi dan Aplikasi. Jakarta: PT Indeks.

Nasution, S. 2000. Berbagai Pendekatan dalam Proses Belajar dan 
Mengajar. Jakarta: Bumi Aksara.

Orlich, DC.; R.J. Harder; R.C. Callahan; \& H.W. Gibson. 1998. Teaching Strategies: a Guide to Better Instruction. Boston: Houghton Mifflin.

Rusli Lutan. 1996. Ilmu Keolahragaan dan Beberapa Isu Filosofis Manusia dan Olahraga. Bandung: Penerbit ITB.

Russel, J.D. 1974. Modular Instructional: a Guide to the Design, Selection, Utilization and Evaluation of Modular Materials. Minneapolish, Minnesota: Burgess.
Slavin. R.E. 1997. Educational Psichology: Theory and Practise, $5^{\text {th }}$ Ed. Boston: Allyn and Bacon.

Suherman, wawan. 2007. Perlunya pendidikan Jasmani Bagi Anak.

Suryobroto, B. 1983. Sistem Pengajaran dengan Modul. Yogyakarta: Bina Aksara.

Winataputra, dkk. 1997. Panduan Operasional Penulisan Modul. Jakarta: Depdikbud-UT FKIP.

Woolfolk, A. 1995. Educational Psychology, $6^{\text {th }}$ ed. Boston. Allyn and Bacon. 